\title{
Utilization of Cloud Computing Services (CCS) in the University Library System in Sri Lanka
}

\author{
K.A.T. Chamara ${ }^{1}$, N. Hettiarachchi ${ }^{2}$ and Prof. W.A. Weerasooriya ${ }^{3}$ \\ ${ }^{1,3}$ Department of Library and Information Science, University of Kelaniya, Sri Lanka \\ ${ }^{2}$ Main Library, University of Ruhuna, Sri Lanka
}

\begin{abstract}
Cloud Computing (CC) has become an emerging concept which is hosting multiple services via the internet instead of using locally hosted servers. Through the cloud-based services, libraries have the opportunity to uplift their storage, universal accessibility, efficiency and user interaction. Sri Lankan university libraries are keen on gaining knowledge regarding new technological advancements including cloud computing and have started adopting Cloud Computing Services (CCS) for functioning the library activities efficiently. The studies based on the use of CCS in the libraries have not been researched thoroughly in the Sri Lankan context yet. This study mainly focuses to identify the utilization of CCS in the university library system. The study employed quantitative research methodology while using the survey method to collect data and structured questionnaires were distributed among 15 university libraries recognized by the University Grants Commission (UGC) in Sri Lanka. The results of the study indicated that the majority of university libraries tend to use CCS without a satisfactory level of awareness of Cloud Computing Technology (CCT). It is observed that the usage of CCS does not depend on the level of awareness of CCT. The awareness of CCT applications, which can be used in libraries, should be improved through organizing awareness programmes, workshops and hands-on training.
\end{abstract}

Keywords: Cloud Computing; Cloud Computing Services; ICT; Sri Lanka; University Libraries 